\title{
The alphabet soup that protects cold-water corals in the North Atlantic
}

\author{
Robert Brock $^{1, *}$, Elizabethann English ${ }^{2}$, Ellen Kenchington ${ }^{3}$, Mark Tasker $^{4}$ \\ ${ }^{1}$ NOAA Fisheries Service, Office of Science and Technology, 1315 East-West Highway, Silver Spring, Maryland 20910, USA \\ ${ }^{2}$ NOAA Fisheries Service, Office of International Affairs, 1315 East-West Highway, Silver Spring, Maryland 20910, USA \\ ${ }^{3}$ Fisheries and Oceans Canada, 1 Challenger Drive, Dartmouth, Nova Scotia B2Y 4A2, Canada , \\ ${ }^{4}$ Joint Nature Conservation Committee, 7 Thistle Place, Aberdeen AB10 1UZ, UK
}

\begin{abstract}
Canada, the European Union, and the United States, amongst others, recognize the importance of habitat-forming biota such as cold-water corals to a host of associated ecologically and/or commercially important species including fish, crustaceans, and mollusks. These species and the ecological services they provide are important to the peoples surrounding the North Atlantic (i.e. the Atlantic Ocean north of the equator). There are several different legal and/or regulatory tools available to ensure that cold-water corals in the North Atlantic are protected along with the ecological services they provide. Through such tools, many protected areas have been designated or are under consideration in the North Atlantic to protect cold-water coral habitats. Although the designation and labeling varies, e.g. National Marine Conservation Area (Canada), Special Area of Conservation (European Union), or Habitat Area of Particular Concern (USA), all of these designations aim to provide protection into the future to vulnerable habitats like cold-water corals.
\end{abstract}

KEY WORDS: Habitat protection - Cold-water corals · Vulnerable marine ecosystems · Marine protected areas $\cdot$ Biodiversity $\cdot$ North Atlantic

Resale or republication not permitted without written consent of the publisher

\section{INTRODUCTION}

The impacts of certain fishing practices, such as bottom-tending mobile gears, on vulnerable marine ecosystems (VMEs), including cold-water corals, have been intensely debated in a variety of international forums in recent years, e.g. the United Nations General Assembly (UNGA), the Food and Agriculture Organization (FAO) and the Convention on Biological Diversity (CBD). The 2006 UNGA Sustainable Fisheries Resolution (A/Res/61/105) reviewed domestic and international progress on protecting VMEs from destructive fishing practices. Resolution 61/105 calls for specific actions to be taken by states and regional Fisheries Management Organizations and Arrangements (RFMO/A), and the FAO. Member countries are to adopt and implement relevant measures to identify and protect VMEs by 31 December 2008, or to cease authorizing bottom fishing in these areas. As the UNGA is looking for countries to make progress in implementing this Resolution, the Northwest Atlantic Fisheries Organization (NAFO) and the North East Atlantic Fisheries Commission (NEAFC) (both RFMOs) have both recently adopted management measures in the North Atlantic ${ }^{1}$ that comply with the requirements of the UNGA to protect VMEs that can include coldwater corals habitats.

Although countries are not required to implement the measures of Resolution 61/105 within their own exclusive economic zones (EEZs), the EU, Canada, and the US each have taken steps to protect VMEs such as cold-water corals from significant adverse impacts from fishing practices within waters under their jurisdictions. In both the multilateral and domestic context, management measures being undertaken to protect

\footnotetext{
${ }^{1}$ As the Exclusive Economic Zones of the US includes areas such as Puerto Rico, Navassa Island, and the US Virgin Islands, the North Atlantic in this paper is defined as the Atlantic Ocean north of the equator.
} 
cold-water corals are an 'alphabet soup' of differing terms (e.g. EFH, MPA, CHAPC, HADD, EBSA, LOMA, and $\mathrm{SAC}_{\text {; }}$ see Appendix 1). However, the goals of all of these measures are strikingly similar: to identify areas and/or habitats that are vulnerable to anthropogenic activities, determine the impact of fishing and other industrial practices (e.g. marine mining, cable laying, energy exploration, and development) in these areas, and take subsequent actions to protect the habitat and the ecological services they provide.

\section{PROTECTING COLD-WATER CORALS IN CANADIAN WATERS}

Protection of cold-water corals in Canada was originally provided under the Fisheries Act (Department of Justice Canada 1985) through which it is illegal to cause harmful alteration, disruption, or destruction of fish habitat, which includes cold-water corals. This Act remains one of Canada's strongest environmental legislations and has been in existence since the time of Confederation (1867), although federal versus provincial authority over fish and fish habitat was not clearly established until 1982 through the Constitution Act. In 2002 and 2004 the Fisheries Act was used to establish fisheries closures in 2 areas off the coast of Nova Scotia to protect high concentrations and rare occurrences of corals, respectively: the Northeast Channel Coral Conservation Area and the Lophelia Coral Conservation Area.

In 1996, the Oceans Act was introduced (Department of Justice Canada 1996). Fisheries and Oceans Canada (DFO), under the authority of the Oceans Act, can establish Marine Protected Areas (MPAs, http://mpa.gov) in marine waters under Canada's jurisdiction for the conservation and protection of fish and other living marine resources and their habitats; of endangered and threatened species and their habitats; of marine areas of high biodiversity or biological productivity; of unique habitats; or any other reason pursuant to the mandate of the Minister of Fisheries and Oceans. Seven MPAs have been established, but not all of them offer protection to cold-water corals. Of these, the Gully MPA on the east coast and the Bowie Seamount MPA on the west coast offer the greatest protection to cold-water coral species. The Oceans Act also calls for integrated oceans management and as part of that process the DFO has identified ecologically and biologically significant areas (EBSA) and documented research requirements associated with each. Benthic invertebrates, which of course include corals, are one of the biological components assessed.

In 2002, the National Marine Conservation Areas Act (Department of Justice Canada 2002) was passed, which allows for the closure of areas for the purpose of protecting and conserving representative marine areas. National Marine Conservation Areas (NMCAs) are marine areas managed for sustainable use and contain smaller zones of high protection. They include the seabed, the water above it, and any species that occur there. Three NMCAs have been established thus far, but only one, the Saguenay-St. Lawrence Marine Park, may offer protection to cold-water corals.

In 2007, NAFO and Canada announced the immediate closure of a coral protection zone in NAFO Division $3 \mathrm{O}$ (mostly within Canada) on the Grand Banks off the southeast coast of Newfoundland and Labrador. For a 5 -yr period beginning in 2008 , this area will be closed to all bottom-contact fishing gear. Fig. 1 illustrates the size, location, and depth of the areas comprising Canada's cold-water coral protection efforts.

\section{PROTECTING COLD-WATER CORALS IN EU WATERS}

The protection of coral reefs in EU waters occurs under 2 separate but related parts of EU legislation: that for protecting biodiversity and that for managing fisheries.

The main EU instrument for protecting biodiversity is the Habitats Directive (92/43/EEC; Council of the European Communities 1992). This Directive obliges EU Member States to ensure that certain habitats (and species) are in 'favourable conservation status'; among the habitats listed are reefs. One of the mechanisms to ensure favourable conservation status is the establishment of Special Areas of Conservation (SAC). Management of human activities in these areas should be to ensure that the features are maintained in a favourable condition (or in some cases are restored and/or allowed to recover to that condition). The application of this Directive in EU waters has, until the current decade, been entirely coastal. A series of legal rulings clarified that the Directive applied to all areas (in European waters) over which a Member State had jurisdiction, thus including the EEZ (where they existed) and any areas over which continental shelf extensions were claimed.

Reef habitat under the Habitats Directive includes many more features than cold-water corals, so there are many reef SACs in EU waters, but only 2 that contain cold-water corals. These are the Darwin Mounds (UK) and a series of sites on the Porcupine Bank (Ireland). Further sites are in various stages of progress, including NW Rockall (UK), Mingulay (UK) and El Cachucho (also known as Le Danois Bank; Spain). Once sites reach a certain stage in the designation process, Member States are obliged to take measures to protect them. However, in the case of protection from fisheries, this is complicated by the EU's Common Fisheries Policy which all fisheries management measures must comply with. For waters beyond 6 nautical 


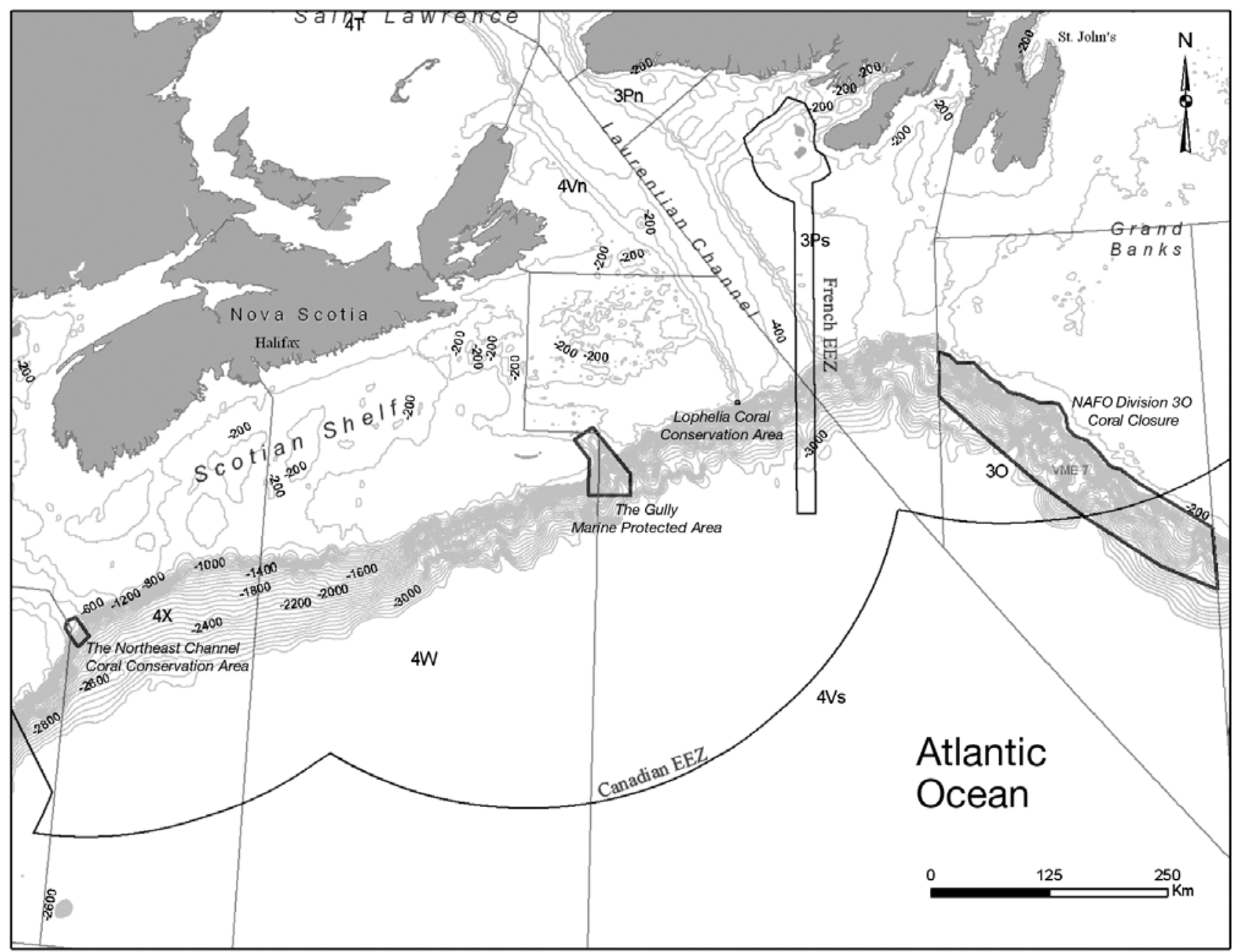

Fig. 1. Coral closure areas on the Scotian Shelf and Grand Banks (thick black lines). From left to right, the Northeast Channel Coral Conservation Area, the Gully Marine Protected Area, the Lophelia Coral Conservation Area and the NAFO Division 30 Coral Closure (extending outside of the exclusive economic zone of Canada). EEZ: Exclusive Economic Zone

miles (n miles) from the coastal baseline, these measures require international agreement, and for waters beyond $12 \mathrm{n}$ miles, measures can only be proposed by the European Commission and agreed collectively by the European Council of Ministers. Member States of the EU are required to submit a case for protection covering a number of issues to the Commission, who then seek scientific and technical advice on the proposal before deciding whether to apply fishing regulations.

Fisheries regulations may also be applied to protect sensitive habitats directly, independently of whether a site has been formally proposed by a Member State. This is because the base legislation of the Common Fisheries Policy (Council Regulation 2371/2002) has a number of articles requiring that measures be taken to protect the ecosystem from damage caused by fishing activities. These are the articles that are used to regulate (usually ban) fishing activity in SACs, but also to ban (currently) fishing on Hatton Bank and parts of the
Rockall Bank and nearby areas. The legislation also can be applied to vessels fishing under EU Member State registration in waters regulated by the NEAFCcurrently such areas containing (or likely to contain) cold-water corals that are closed to European fleets include the Hecate, Faraday, Altair and Antialtair seamounts and part of the Reykjanes Ridge. Seamounts near the Azores are also protected from bottom-fishing activities.

\section{PROTECTING COLD-WATER CORALS IN US WATERS}

The NOAA National Marine Fisheries Service (NMFS) has dedicated significant effort to studying the effects of various fishing gears as they relate to their impact on habitats such as cold-water corals. The US Government has identified a number of tools available to mitigate the impacts of fishing practices on vulnera- 
ble habitats, including designating areas as Federal Fisheries Management Zones, Essential Fish Habitat (EFH), Habitat Areas of Particular Concern (HAPC; NOAA 2009), National Monuments, and MPAs.

NMFS is currently undertaking numerous research projects to improve the understanding of the effects of fishing gears on EFH. EFH is defined as those waters and substrate necessary to fish for spawning, breeding, feeding, or growth to maturity (NOAA 2008). The Magnuson-Stevens Fishery Conservation and Management Act (MSFCMA; NOAA 2007) requires the nation's 8 regional fishery management councils (Councils) to identify, describe, conserve, enhance, and minimize the adverse effects of fishing on EFH. Within EFHs, the Councils and NOAA further designate HAPC based on: (1) the importance of the ecolog- ical function provided by the habitat; (2) the extent to which the habitat is sensitive to human-induced environmental degradation; (3) whether, and to what extent, the development activities are, or will be, stressing the habitat type; and (4) the rarity of the habitat.

Management measures have been taken to reduce adverse fishing impacts on these designated coral habitats, which include some rare cold-water coral species (e.g. Oculina varicosa). The South Atlantic Fishery Management Council (SAFMC) has established several HAPC to protect cold-water corals (e.g. Lophelia pertusa). As recently as January 2009, the SAFMC designated 8 Coral HAPC (CHAPC) to protect a portion of the habitat that is vital to long-living, deepwater fish species (Fig. 2).

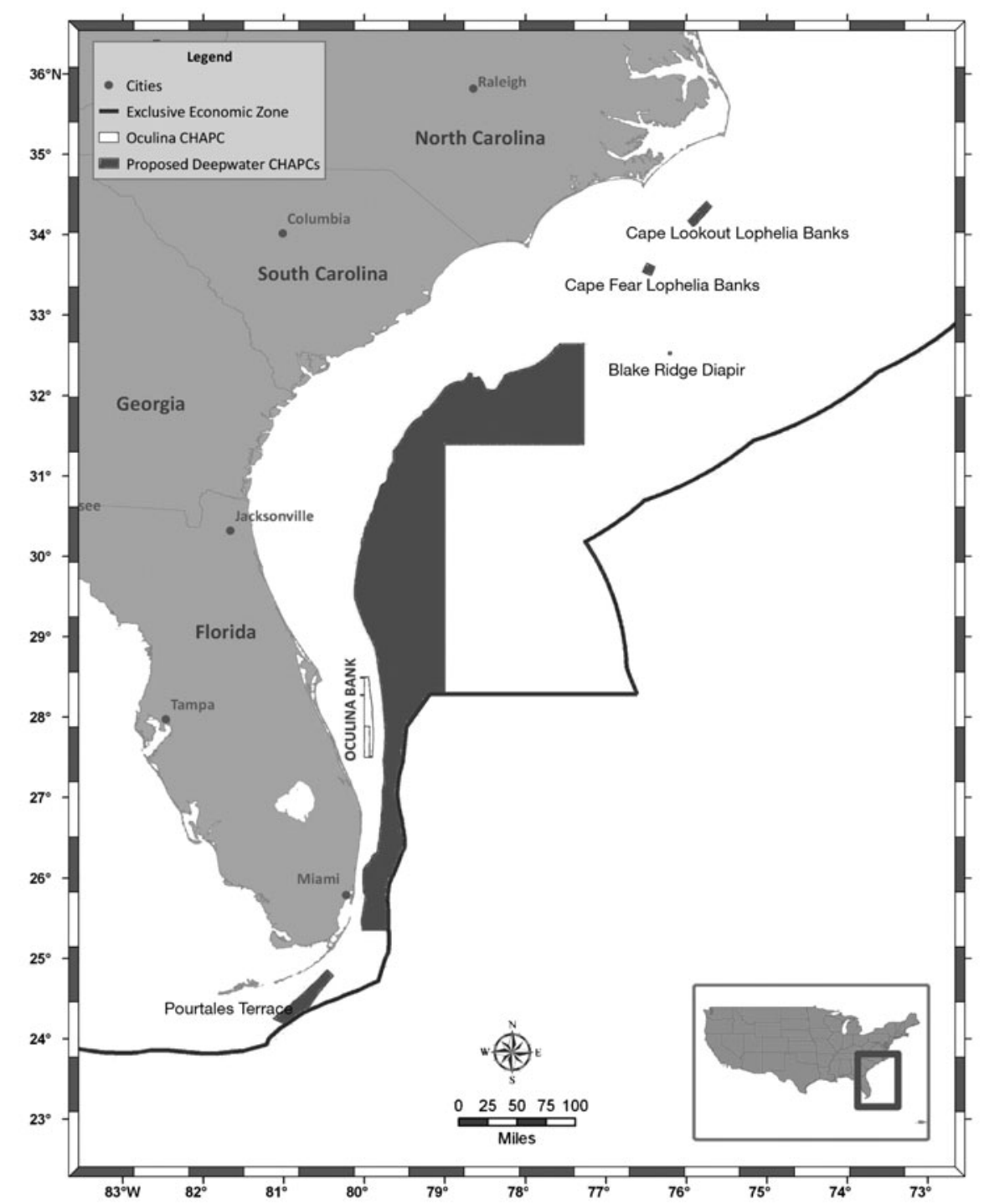

Fig. 2. Proposed deep-water Coral Habitat Areas of Particular Concern (CHAPC) in the southeastern United States (courtesy of T. Udouji, Florida Fish and Wildlife Conservation Commission) 
In addition to EFH, HAPC, and CHAPC, area-based protection of VMEs can be achieved through MPA or national monument designation. Under the National Marine Sanctuaries Act, as amended, the Secretary of Commerce is authorized to designate and manage areas of the marine environment with special national significance due to their conservation, recreational, ecological, scientific, educational, or aesthetic qualities as National Marine Sanctuaries. The primary objective of this law is to protect marine resources such as coral reefs or unique habitats. Sanctuaries, frequently described as national parks of the sea, are managed according to site-specific management plans (such as protecting cold-water coral habitat) prepared by the NOAA Office of National Marine Sanctuaries.

While designations such as EFH and CHAPC are implemented to directly protect habitat such as coldwater corals, there has been many restrictions placed on bottom fishing with the aim of protecting demersal stocks of commercially valuable fish species (e.g. cod, haddock, and flounder). These designations to restrict bottom-tending gear (e.g. bottom-trawling, pots, traps, and longlines) also offer indirect protection to coldwater corals. Restrictions in the northeastern (e.g. Gulf of Maine) and southeastern (e.g. Florida) USA are currently in place in many areas where no fishing gear is allowed to come into contact with the bottom. While implemented to protect demersal fish stocks, these gear restrictions have indirectly benefited cold-water coral and sponge areas as well.

\section{CONCLUSIONS}

Whether it is as substrate for attaching organisms, refuge for juveniles, or areas for aggregating species to feed and spawn, the direct and indirect benefits that habitat provides marine organisms is widely recognized by governments throughout the world. There has been considerable focus in recent years from the UNGA, FAO, and others to protect habitat and their ecological services from the damaging impacts of various anthropogenic activities. This paper has highlighted the efforts of Canada, the EU, and the USA to use legal and/or regulatory tools available to ensure that the important ecological functions and services that various habitat types (especially cold-water corals) provide in the North Atlantic are protected. Although these various legal and/or regulatory tools are called many things around the world, creating an 'alphabet soup' of designations, their aim is clearly similar in that the objective is to protect, through direct and indirect means, habitat such as cold-water corals and the ecological services they provide.

With adoption and implementation of more habitat protection measures, the difficulties of enforcing these restrictions and assessing the efficacy of these restrictions present new challenges. Many countries and RFMOs do not have the technological means, financial resources, or political will to adequately enforce conservation measures (especially on the high seas) or fund projects to monitor how well these conservations measures are fulfilling their objectives and what adaptive management measures might be appropriate. The need to protect newly discovered areas of cold-water corals is obvious, whereas the resources necessary to design, adopt, and implement appropriate protective measures is not always as clear. This challenge will likely continue to grow in importance as will our desire for deep-water fisheries, minerals, oil and gas.

\section{LITERATURE CITED}

Department of Justice Canada (1985) Fisheries Act, Chapter F-14. Minister of Justice, available at http://laws.justice. gc.ca/en/F-14/

Department of Justice Canada (1996) Oceans Act, S.C., 1996, c. 31. Minister of Justice, available at http://laws.justice. gc.ca/en/O-2.4/

Department of Justice Canada (2002) Canada National Marine Conservation Areas Act, S.C., 2002, c. 18. Minister of Justice, available at http://laws.justice.gc.ca/en/C-7.3/ index.html

Council of the European Communities (1992) Council Directive 92/43/EEC of 21 May 1992 on the conservation of natural habitats and of wild fauna and flora. Off $\mathrm{J}$ Eur Union 206:7-50, available at http://ec.europa.eu/environment/ nature/legislation/habitatsdirective/index_en.htm

NOAA (2007) Magnuson-Stevens Fishery Conservation and Management Reauthorization Act. NOAA, available at www.nmfs.noaa.gov/msa2007/

NOAA (2008) Essential fish habitat. What is essential fish habitat? NOAA, Office of Habitat Conservation, Habitat Protection Division, available at www.nmfs.noaa.gov/ habitat/habitatprotection/efh/index_a.htm

NOAA (2009) What are habitat areas of particular concern (HAPC)? NOAA, Office of Habitat Conservation, Habitat Protection Division, available at www.nmfs.noaa.gov/ habitat/habitatprotection/efh/index_b.htm 
Appendix 1. Glossary of terms

CHAPC - Coral Habitat Area of Particular Concern (CHAPCs) are coral areas that provide extremely important ecological functions or are especially vulnerable to degradation.

EBSA - Ecologically and Biologically Significant Areas (EBSAs) as designated by the Convention on Biological Diversity (www.cbd.int) are marine areas in need of special protection as they are (1) unique or rare; (2) have special importance for various life history stages of species (3) are important to threatened, endangered or declining species and/or habitats; (4) are considered vulnerable, fragile, sensitivite, or slow to recover from disturbance; (5) areas of high biological productivity; (6) areas of high biological diversity; and (7) exhibit a strong sense of naturalness.

EFH - Essential Fish Habitat is defined as those waters and substrate necessary to fish for spawning, breeding, feeding, or growth to maturity.

FAO - The Food and Agricultural Organization of the United Nations is based in Rome, Italy, and the FAO Department of Fisheries and Aquaculture promotes policies and strategies aimed at sustainable and responsible development of fisheries and aquaculture in inland and marine waters. The FAO has developed expert advice on responsible fishing practices on the high seas and protection of vulnerable marine ecosystems.

FMP - Fishery Management Plans are developed in the USA for all commercially and recreationally significant species or fisheries and contain management goals and objectives, status of the relevant fish stocks, stock assessments for multi-year species, and fishery habitat and water quality considerations.

HADD - Under Canada's Fisheries Act, 'no person shall do any work that results in the harmful alteration, disruption or destruction of fisheries habitat' unless authorized; any project must be assessed as to its potential harm prior to work being undertaken.

LOMA - Large Ocean Management Areas (LOMAs) are marine regions established for planning purposes. They form the planning basis for implementation of integratedmanagement plans. LOMAs are typically hundreds of square kilometres in size. Their boundaries are determined using a combination of ecological and administrative considerations. See Fisheries and Oceans Canada: www.dfompo.gc.ca/oceans/marineareas-zonesmarines/loma-zego/ purpose-but-eng.htm

MPA - A Marine Protected Area as defined by Executive Order 13158, signed by President Clinton in May 2000, is 'any area of the marine environment that has been reserved by federal, state, tribal, territorial, or local laws or regulations to provide lasting protection for part or all of the natural and cultural resources therein.'

RFMO/A - Regional Fisheries Management Organizations and Arrangements are responsible for managing fish stocks on the high seas and fish stocks that migrate through the waters of more than just a single country.

SAC - Special Areas of Conservation are strictly protected sites designated under the EC Habitats Directive (92/43/ $\mathrm{EEC}_{i}$ Council of the European Communities 1992). The listed habitat types and species are those considered to be most in need of conservation (excluding birds). Available at: www.naturalengland.org.uk/ourwork/conservation/ designatedareas/sac/default.aspx.

VME - Vulnerable Marine Ecosystems are sensitive habitats defined as those that are easily affected by human disturbance and can be expected to take a long time to recover from these disturbances, if ever. 